\title{
Aquatic insects dealing with dehydration: do desiccation resistance traits differ in species with contrasting habitat preferences?
}

\author{
Susana Pallarés ${ }^{\text {Corresp., }}{ }^{1}$, Josefa Velasco ${ }^{1}$, Andrés Millán ${ }^{1}$, David T. Bilton ${ }^{2}$, Paula Arribas ${ }^{3,4,5}$ \\ 1 Department of Ecology and Hydrology, Universidad de Murcia, Murcia, Spain \\ 2 Marine Biology and Ecology Research Centre, School of Marine Science and Engineering, University of Plymouth, Plymouth, United Kingdom \\ 3 Department of Life Sciences, Natural History Museum London, London, United Kingdom \\ 4 Department of Life Sciences, Imperial College London, London, United Kingdom \\ 5 Island Ecology and Evolution Research Group, IPNA-CSIC, La Laguna, Tenerife, Spain \\ Corresponding Author: Susana Pallarés \\ Email address: susana.pallares@um.es
}

Background. Desiccation resistance shapes the distribution of terrestrial insects at multiple spatial scales. However, responses to drying stress have been poorly studied in aquatic groups, despite their potential role in constraining their distribution and diversification, particularly in arid and semi-arid regions. Methods. We examined desiccation resistance in adults of four congeneric water beetle species (Enochrus, family Hydrophilidae) with contrasting habitat specificity (lentic vs lotic systems and different salinity optima from fresh- to hypersaline waters). We measured survival, recovery capacity and key traits related to desiccation resistance (fresh mass, \% water content, \% cuticle content and water loss rate) under controlled exposure to desiccation, and explored their variability within and between species. Results. Meso- and hypersaline species were more resistant to desiccation than freshwater and hyposaline ones, showing significantly lower water loss rates and higher water content. No clear patterns in desiccation resistance traits were observed between lotic and lentic species. Intraspecifically, water loss rate was positively related to specimens' initial \% water content, but not to fresh mass or \% cuticle content, suggesting that the dynamic mechanism controlling water loss is mainly regulated by the amount of body water available. Discussion. Our results support previous hypotheses suggesting that the evolution of desiccation resistance is associated with the colonization of saline habitats by aquatic beetles. The interespecific patterns observed in Enochrus also suggest that freshwater species may be more vulnerable than saline ones to drought intensification expected under climate change in semi-arid regions such as the Mediterranean Basin. 
1 Aquatic insects dealing with dehydration: do desiccation resistance traits differ in species with contrasting habitat preferences?

3 SUSANA PALLARÉSa, JOSEFA VELASCO ${ }^{a}$, ANDRÉS MILLÁNa , DAVID T. BILTON , PAULA ARRIBAS ${ }^{\mathrm{c}, \mathrm{d}, \mathrm{e}}$

5 a Department of Ecology and Hydrology, University of Murcia, Murcia, Spain

6 b Marine Biology and Ecology Research Centre, School of Marine Science and Engineering,

7 Plymouth University, Plymouth, United Kingdom

8 c Department of Life Sciences, Natural History Museum London, London, United Kingdom

9 d Department of Life Sciences, Imperial College London, London, United Kingdom

10 e Island Ecology and Evolution Research Group, IPNA-CSIC, La Laguna, Spain

\section{Corresponding author:}

13 Susana Pallarés

14 Dpto. Ecología e Hidrología, Fac. Biología

Campus Espinardo - Universidad de Murcia

30100 Espinardo (Murcia) Spain 


\section{Abstract}

26 Background. Desiccation resistance shapes the distribution of terrestrial insects at multiple

27 spatial scales. However, responses to drying stress have been poorly studied in aquatic groups,

28 despite their potential role in constraining their distribution and diversification, particularly in

29 arid and semi-arid regions.

Methods. We examined desiccation resistance in adults of four congeneric water beetle species

(Enochrus, family Hydrophilidae) with contrasting habitat specificity (lentic $v s$ lotic systems and different salinity optima from fresh- to hypersaline waters). We measured survival, recovery capacity and key traits related to desiccation resistance (fresh mass, \% water content, \% cuticle content and water loss rate) under controlled exposure to desiccation, and explored their variability within and between species.

Results. Meso- and hypersaline species were more resistant to desiccation than freshwater and hyposaline ones, showing significantly lower water loss rates and higher water content. No clear patterns in desiccation resistance traits were observed between lotic and lentic species. Intraspecifically, water loss rate was positively related to specimens' initial \% water content, but not to fresh mass or $\%$ cuticle content, suggesting that the dynamic mechanism controlling water loss is mainly regulated by the amount of body water available.

Discussion. Our results support previous hypotheses suggesting that the evolution of desiccation resistance is associated with the colonization of saline habitats by aquatic beetles. The interespecific patterns observed in Enochrus also suggest that freshwater species may be more vulnerable than saline ones to drought intensification expected under climate change in semi-arid regions such as the Mediterranean Basin. 


\section{Introduction}

48 Maintaining water balance is fundamental for organismal survival, small animals such as insects

49 being especially vulnerable to dehydration (Addo-Bediako et al. 2001). Desiccation resistance

50 therefore shapes the distribution of insect species at multiple spatial scales, both ecologically and

51 biogeographically (Kellermann et al. 2009), and will determine the way insect taxa respond to

52 increased temperatures and greater seasonal fluctuations in water availability in the face of

53 climate change (Chown et al. 2011).

54 The role of desiccation resistance for insect vulnerability could be particularly important in arid

55 and semiarid regions such as the Mediterranean Basin. In these areas, many lowland inland

56 waters show spatial and temporal flow intermittency, because they are subjected to intense

57 summer droughts (Hershkovitz and Gasith 2013; Millán et al. 2011). During the dry period,

58 some small and shallow lentic waterbodies can remain completely dry for months. In intermittent

59 streams, flow connectivity is disrupted; some reaches dry out while others can retain water in

60 receding pools. The predicted increase of the duration and frequency of droughts in

61 Mediterranean-climate regions in the context of global change threatens the persistence of many

62 of their endemic aquatic organisms (Filipe et al. 2013; IPCC 2013; Lawrence et al. 2010).

63 However, a large knowledge gap still exists in the way aquatic macroinvertebrates respond to

64 droughts (Robson et al. 2011). In the case of aquatic insects, most studies are focused on

65 desiccation-resistant eggs or dormant larvae stages (e.g. Benoit 2010; Juliano et al. 2002; Woods

66 and Singer 2001), but little is known on the effects of dryness on species which lack these

67 resistant stages (e.g. most aquatic beetles, Strachan et al. 2015). Although some species of water

68 beetles resist the dry phase of temporary waters in microrefuges in situ, as adult or larvae stages

69 (e.g. Davy-Bowker 2002; Stubbington et al. 2016), winged adults of many species show a more 
70 resilient strategy, dispersing by flying from drying sites to more favourable wet habitats (Bilton

71 2014; Strachan et al. 2015). The duration of exposure to drying stress during dispersal depends

72 on specific biological traits (e.g. flight ability) and landscape configuration, i.e. the availability of

73 suitable habitats that may serve as wet refuges and the distance and connectivity between them

74 (Datry et al. 2016; Larned et al. 2010). But even short exposures to drying stress are challenging

75 for flying aquatic insects, because flight activity is associated to a strong dehydration (Dudley

76 2000).

77 Studies of geographical variation in responses to desiccation stress in terrestrial insects have

78 typically demonstrated that species and populations from xeric environments show a greater

79 ability to deal with dehydration than those from mesic areas (e.g. Chown 1993; Gibbs and

80 Matzkin 2001; Le Lagadec et al. 1998; Schultz et al. 1992). Different responses to desiccation

81 have also been related to patterns of habitat and microhabitat choice in arthropods (e.g. Chown

82 1993; De Vito et al. 2004; Gereben 1995; Lapinski and Tschapka 2014), including aquatic

83 species (e.g. Wissinger et al. 2003; Yoder et al. 2015). In general, these studies show that some

84 physiological mechanisms linked to drying stress such as the control of water loss rate have an

85 important plastic and adaptive component, whilst others, such as the tolerance of water loss, are

86 less variable across species (Chown et al. 1999; Hoffmann and Harshman 1999). In inland water

87 ecosystems, even congeneric macroinvertebrate species show remarkable differences in the

88 strategies and particular traits to deal with desiccation, and such variability is strongly associated

89 with the frequency and duration of droughts in their habitats (Strachan et al. 2015).

90 In Mediterranean inland waters, a number of genera of water beetles belonging to different

91 families contain species which are adapted to different parts of the fresh - hypersaline gradient

92 (Millán et al. 2011). Organisms dealing with osmotic stress in saline waters face similar 
93 physiological challenges to those imposed by desiccation; i.e. maintaining water balance and

94 compensating for the increase in the osmotic concentration of internal fluids (Bradley 2009). In

95 light of this, interspecific differences in desiccation resistance may correlate with salinity

96 tolerance, so that species inhabiting saline waters are expected to be potentially more resistant to

97 desiccation than those in lower salinity ranges (Arribas et al. 2014). In addition, species living in

98 relatively short-lived small lentic water bodies, which are more unstable systems over

99 evolutionary and ecological time-scales than lotic systems (see Ribera 2008 for details), may also

100 be expected to have higher desiccation resistance compared to related lotic taxa. These

101 predictable differences have already been found between lotic and lentic congeneric beetle

102 species in other traits such as dispersal capacity (Arribas et al. 2012), behavioural responses to

103 acute thermal stress (Pallarés et al. 2012) and salinity tolerance (Céspedes et al. 2013).

104 Together with behavioural responses (e.g. use of microrefuges, burrowing) or aestivation,

105 invertebrates have evolved a variety of physiological adaptations to cope with desiccation stress

106 (Hershkovitz and Gasith 2013; Strachan et al. 2015). These fall under two main strategies

107 (Chown and Nicolson 2004; Edney 1997): 1) avoiding desiccation through the reduction of water

108 loss and increases in body water content (desiccation resistance, e.g. Gray and Bradley 2005)

109 and 2) withstanding the loss of a significant proportion of body water (desiccation tolerance, e.g.

110 Benoit et al. 2007; Suemoto et al. 2004). In insects, mechanisms regulating cuticle permeability

111 are the major component of desiccation resistance because the cuticle represents their main

112 avenue for water loss (Benoit et al. 2010; Chown and Nicolson 2004; Hadley 1994). Cuticle

113 permeability is related with the cuticle thickness (Crowson 1981; Harrison et al. 2012;

114 Reidenbach et al. 2014), but can be actively regulated through changes in the amount and

115 composition of surface lipids (Gibbs and Rajpurohit 2010; Stinziano et al. 2015). Water loss has 
116 shown to be non-linear following exposure to desiccation in a range of taxa (e.g. Benoit et al.

117 2007; Arlian and Staiger 1979). Greater water loss rates occur during initial hours of exposure

118 and decrease as body water content approaches lethal levels, suggesting that water loss is

119 actively regulated by dynamic mechanisms. As a consequence, the water content of an individual

120 at a particular moment could influence its water loss dynamics and ultimately its survival under

121 drying stress. On the other hand, body size can affect desiccation resistance in arthropods in a

122 number of ways. In general, larger body mass allows a higher proportion of water and lipid

123 content (Lighton et al.1994; Prange and Pinshow 1994), and additionally smaller insects may

124 show higher mass-specific water loss rates due to higher surface area - volume ratios (Chown et

125 al. 1998; Schmidt-Nielsen 1984; Williams and Bradley 1998). Such effects of size on water loss

126 rates have been seen both inter- (e.g. Chown and Klok 2003; Le Lagadec et al. 1998) and

127 intraspecifically (e.g. Renault and Coray 2004).

128 Here we compared responses to desiccation stress in flying adults of four aquatic beetle species

129 of the genus Enochrus. These species are specialists of either lentic or lotic waters of differing

130 salinity, providing an ideal model to explore the potential relationship between specific

131 desiccation resistance traits of aquatic insects and the main inland waters habitat types. We

132 measured their survival and recovery ability following controlled exposure to drying stress and

133 explored key traits related to desiccation resistance to: i) determine whether congeneric species

134 with different habitat preferences differ in desiccation resistance and ii) explore the extent to

135 which inter-individual differences in water loss rates are shaped by body size, cuticle thickness

136 and/or water content in these insects. We predicted that species from most saline habitats would

137 show higher desiccation resistance than less saline tolerant ones. Additionally, species living in

138 lentic waters could have evolved a higher resistance to desiccation than lotic ones. 
139 Material and methods

140 Study species

141 The genus Enochrus (Coleoptera: Hydrophilidae) has representatives living across a wide variety

142 of inland waters of differing salinities (from $0.5 \mathrm{~g} / \mathrm{L}$ to $>80 \mathrm{~g} / \mathrm{L}$ in the study area). The four

143 species used in this study show different salinity ranges and optima both in laboratory (Pallarés

144 et al. 2015) and nature (Arribas et al. 2014): E. halophilus (Bedel, 1878) (fresh-subsaline

145 waters), E. politus (Kuster, 1849) (hyposaline), E. bicolor (Fabricius, 1792) (mesosaline) and E.

146 jesusarribasi Arribas and Millán, 2013 (hypersaline). All species live in shallow water close to

147 the margins of occupied water bodies, but differ in their habitat preferences across the lentic-lotic

148 divide, being found in lentic (E. halophilus and E. bicolor) and lotic waters (E. politus and E.

149 jesusarribasi) (see Table 1 for more detailed habitat information). These species do not show any

150 resistant form to face desiccation in situ at any stage of their life cycle. Therefore, their main

151 strategy to deal with droughts in temporal and/or intermittent systems relies on the dispersal

152 ability of adults, which move from drying to wet sites. These movements may occur between

153 different or within the same waterbodies, depending on the landscape configuration and habitat

154 availability (Datry et al. 2016; Larned et al. 2010).

155 Experimental procedures

156 Adult specimens (approx. 50 per species) were collected from different localities all in

157 southeastern Spain and representing the optima salinity conditions of each species (see Table 1).

158 For logistic reasons, we used specimens from one single location per species. Such locations

159 were selected minimizing distances between each other and so have a comparable climatic

160 regime. All species were collected during the spring 2014, therefore the specimens used for the 
161 experiments were all mature adults from the winter generation and presumably had not been

162 previously exposed to desiccation stress in natural conditions.

163 Specimens were maintained for 4-7 days in the laboratory at $20 \pm 1^{\circ} \mathrm{C}$ in aerated tanks with water

164 from collection sites (i.e. at the same salinity of their habitat) and fed with macrophytes also

165 collected in the source localities. For comparative purposes, insects were kept $48 \mathrm{~h}$. before

166 desiccation experiments in a dilute medium (ca. $0.1 \mathrm{mS} \mathrm{cm}^{-1}$ ) at $20 \pm 1^{\circ} \mathrm{C}$ and 12:12 light:day

167 cycle in a climatic chamber (SANYO MLR-351, Sanyo Electric Co., Ltd., Moriguchi City,

168 Osaka, Japan), without access to food. The medium was prepared by dissolving the appropriate

169 amount of marine salt (Ocean Fish, Prodac, Cittadella, Italy) in distilled water.

170 The experimental protocol and variables recorded in controlled desiccation experiments are

171 showed in Fig. S1. For each specimen studied we obtained the initial fresh mass $\left(\mathrm{M}_{0}\right)$ as a

172 surrogate of size, initial water content ( $\mathrm{WC}_{0} ; \%$ wet mass to initial fresh mass), cuticle content as

173 a surrogate of cuticle thickness (CC; \% of cuticle mass to initial fresh mass), water loss rates

174 (WLR; \% of water lost to initial fresh mass per unit time) and total water loss after the

175 corresponding treatment (WL, \% of water loss to total water content). For this, groups of 20-25

176 individuals of each species were dried on blotting paper, weighed on a balance accurate to 0.01

$177 \mathrm{mg}$ and placed individually into clean $15 \mathrm{~mL}$ open glass vials. These were kept for $6 \mathrm{~h}$ in a glass

178 desiccator containing silica gel (Sigma-Aldrich, Madrid, Spain) at $20 \pm 1^{\circ} \mathrm{C}$. Relative humidity,

179 monitored with a hygrometer (OM-EL-USB-2-LCD, Omega Engineering, Seville, Spain),

180 dropped from approx. $40 \%$ (laboratory humidity) to $20 \pm 5 \%$ within the first $2 \mathrm{~h}$ and remained

181 stable within this range until the end of the trial. The experimental conditions were optimized

182 trough pilot trials in order to detect differences among species, within their tolerance limits and

183 in a reasonable experimental time (to avoid additional stress such as starvation). The remaining 
184 specimens $(\mathrm{N}=10-20$ individuals per species $)$ were used as a control under no desiccation stress.

185 They were kept in glass vials placed in a closed tank with deionized water in the base, producing

186 a relative humidity $\geq 90 \%$. After 6 h, surviving specimens from control and test groups were re-

187 weighed for estimation of water loss rates and allowed to recover for $24 \mathrm{~h}$ in $100 \mathrm{~mL}$ containers

188 with $40 \mathrm{~mL}$ of the dilute solution. Some studies have shown that rehydration may result in an

189 excessive increase in specimens' water content (overhydration stress, e.g. Lopez-Martinez et al.

190 2009; Yoder et al. 2015). However, we checked in pilot trials (data not shown) that the species

191 here studied recovered their initial water content after rehydration, with no significant water

192 gains. Mortality was monitored after desiccation exposure and after the recovery period.

193 Specimens were then dried at $50^{\circ} \mathrm{C}$ for $48 \mathrm{~h}$ and re-weighed for estimation of the initial water

194 content. A subgroup of 20 individuals per species from the test group were also immersed in 4

$195 \mathrm{~mL}$ of $2 \mathrm{M} \mathrm{NaOH}$ (aq.) for $48 \mathrm{~h}$ at room temperature to allow tissue digestion, rinsed in distilled

196 water, dried and weighed again for estimation of cuticle content (Harrison et al. 2012).

197 Specimens were sexed after the experiment by examining genitalia under a Leica M165C

198 stereomicroscope.

Data analyses

200

201

202

203

204

205

206

Interspecific comparison of desiccation traits

Fresh mass, water loss rate, water content and cuticle content were compared among species using generalized linear models (GLMs) with species as factor, followed by Bonferroni post-hoc tests. Gaussian error distribution and identity link function were used for fresh mass, water content and cuticle content models; and gamma distribution for water loss rate which showed a positively skewed distribution. To account for the potential effects of sex and body size in desiccation resistance, sex and the interaction of sex and species were included as predictors, as 
207 well as fresh mass in comparisons of water loss rate, water content and cuticle content (e.g.

208 Addo-Bediako et al. 2001; Terblanche et al. 2005). Model residuals were checked for normality

209 and homoscedasticity assumptions.

\section{Relationships between desiccation resistance traits within species}

211 To determine the possible effects of initial water content, cuticle content and size (fresh mass) on

212 inter-individual variation in water loss rate, the relationship between water loss rate and each

213 variable was explored for each species separately using GLMs. Gaussian error distribution and

214 identity link function were used when data met a normal distribution. When this assumption was

215 not met, different link functions (log) or different error distributions (Gamma) were

216 implemented, and the model with the lowest AIC was selected.

217 All the statistical analyses were carried out using R v. 3.0.1 (R Core Team 2015).

\section{Results}

Interspecific comparison of desiccation traits

220 The water and cuticle contents of the four studied species ranged from 60 to $68 \%$ and $12-23 \%$

$221 \mathrm{M}_{0}$, respectively. Mean water loss rates of specimens exposed to desiccation ranged from 2.22 to

$2223.57 \% \mathrm{M}_{0} \mathrm{~h}^{-1}$, with a total water loss after $6 \mathrm{~h}$ of desiccation exposure of $19.3-39.1 \% \mathrm{WC}_{0}$.

223 Specimens in the control group showed very little water loss (approx. $0.5 \% \mathrm{M}_{0} \mathrm{~h}^{-1}$ and a

224 maximum water loss of $6 \% \mathrm{WC}_{0}$ ) (see Table $\mathrm{S} 2$ for species comparative data).

225 All desiccation resistance traits differed significantly between species (Table 2). Females showed

226 higher fresh mass and water content than males in all species (see sex and sex x species effects in 
227 Table 2). Despite significant interspecific differences in mean fresh mass (Fig. 1A), the effect of

228 initial body mass on the other trait comparisons was not significant (Table 2).

229 The species living in fresh-subsaline waters (E. halophilus) showed a significantly higher water

230 loss rate, but this did not differ significantly amongst the other three species (Fig. 1B). Initial

231 water content was higher in the meso and hypersaline species (E. bicolor and E. jesusarribasi)

232 than in the subsaline and hyposaline ones (E. halophilus and E. politus) (Fig. 1C). The species

233 showed similar cuticle contents, except for E. halophilus which had the highest value (Fig.1D).

234 No consistent patterns between lotic and lentic species were observed for any of the measured 235 traits.

236 No mortality occurred during exposure to desiccation (except for one specimen of E. halophilus).

237 Enochrus halophilus showed a limited capacity to recover after desiccation (44\% of the tested

238 specimens died during the recovery period $v s$ only one specimen in each of the other species).

239 The observed mortality can be mainly attributed to desiccation stress because $100 \%$ survival

240 occurred in the control group in all species.

241 Relationships between desiccation resistance traits within species

242 In general, the desiccation resistance traits showed high inter-individual variability in all species

243 studied (see Figs. 1 and 2). A significant positive relationship was found between individual

244 water loss rates and water content in all species except for E. halophilus (Fig. 2A). In contrast,

245 cuticle content was not related to water loss rate in any species (Fig.2B), and these were also

246 independent of initial body mass (Fig.2C).

\section{Discussion}


248 On the basis of our investigations, desiccation resistance in Enochrus water beetles appears to be

249 associated with habitat salinity, but does not differ between species occupying lotic and lentic

250 water bodies. The more saline-tolerant species studied (E. bicolor, E. jesusarribasi and E.

251 politus) showed lower water loss rates than the freshwater-subsaline species (E. halophilus).

252 Furthermore, within these three saline species, the meso and hypersaline ones (E. bicolor and $E$.

253 jesusarribasi) had significantly higher initial water content than the hyposaline E. politus.

254 Indeed, these interespecific differences in water control efficiency seem to be relevant in terms

255 of survival under drying stress, as E. halophilus was also the most sensitive species to the

256 conditions tested here. In consequence, assuming that the species may tolerate similar levels of

257 water loss (Chown et al. 1999; Hoffmann and Harshman 1999), the studied saline tolerant

258 species showed a clear physiological advantage over freshwater ones under desiccation

259 conditions.

260 Arribas et al.(2014) suggested that salinity tolerance in water beetles could be based on a co-

261 opted mechanism originally developed for desiccation resistance, relying on the temporal

262 correlation of global aridification events and the phylogenetic ages of saline lineages. The pattern

263 found here of stronger desiccation resistance in aquatic species living in saline waters is clearly

264 consistent with this hypothesis and emphasizes the important role that traits associated with

265 coping with osmotic and desiccation stress could have in shaping the ecological diversification

266 of Enochrus. Also in line with the relationship between desiccation and salinity tolerance seen

267 across the beetles studied here, intraspecific studies of corixid populations found similar

268 responses to the two stressors (e.g. Cannings 1981), and salinity acclimation was showed to

269 confer desiccation resistance in an Antarctic midge (Elnitsky et al. 2009). Salinity imposes

270 similar stress on aquatic organisms as that resulting from desiccation during air exposure at the 
271 cellular level (i.e. water loss and increase of the osmotic pressure) (Evans 2008; Bradley 2009).

272 In consequence, shared genetic and physiological mechanisms might underlie resistance to these

273 two factors, as found with other related stressors such as desiccation and cold (e.g. Everatt et al.

274 2014; Holmstrup et al. 2002; Levis et al. 2012).

275 Our study found no direct association between desiccation resistance and the lotic/lentic habitat

276 divide. Previous studies on water beetles have shown that lentic taxa have a higher colonization

277 ability (i.e. the ability of a species to disperse and establish new populations) than lotic related

278 species, resulting in larger geographical ranges and lower population genetic structure (Abellán

279 et al.2009; Hof et al. 2012; Ribera 2008). Dispersal capacity and thermal tolerance seem to be

280 the main traits driving this lotic/lentic pattern in water beetles (e.g. Hjalmarsson et al. 2015) and

281 particularly in two of the species here studied, E. jesusarribasi and E. bicolor (Arribas et al.

282 2012; Pallarés et al. 2012). The two lotic species studied here are restricted to the Iberian

283 Peninsula and Morocco whilst the lentic ones are distributed across larger areas, including

284 northern Europe (Millán et al. 2014), but no clear patterns in desiccation resistance traits were

285 found accordingly. Therefore, desiccation resistance could play a secondary role to differences in

286 dispersal capacity in shaping the colonization ability of water beetles. In this point it should be

287 noted that Enochrus species' occurrence across different habitat types will be also constrained by

288 the limited desiccation resistance of eggs and larvae, being the latter likely the most desiccation-

289 sensitive stage because of their thinner cuticles. In addition, desiccation resistance might show

290 inter-population variability (e.g. Hoffmann \& Harshman 1999) as a result of physiological

291 plasticity or local adaptations. Despite our study on adults from populations on similar climatic

292 regimes but different habitats allows for a robust comparison across species, further studies on 
293 multiple stages and populations are needed to deeply understand the relationship between habitat

294 occupation and resistance to desiccation in this group.

295 Beetles are one of the groups of arthropods best adapted to desiccation, with species from desert

296 or semi-desert areas typically representing the extremes in tolerance to dehydration. For

297 example, the terrestrial spider beetle Mezium affine shows daily water losses as little as $0.3 \%$ per

298 day and the ability to survive up to 3 months with no food or water (Benoit et al. 2005).

299 Surprisingly, the highest tolerance to water loss ( $89 \%$ of the body water content) has been

300 reported for a fully aquatic beetle, the haliplid Peltodytes muticus (Arlian and Staiger 1979).

301 Since they occupy the shallow margins of waterbodies, Enochrus species may be expected to be

302 intermediate in desiccation resistance between strictly terrestrial beetles and those occupying

303 deeper water such as many diving beetles (Dytiscidae) (Beament 1961; Holdgate 1956;

304 Wigglesworth 1945). However, it is difficult to establish a comparative framework because of

305 the few existent data on desiccation resistance traits in adult aquatic insects and the multiple and

306 contrasting approaches and/or experimental conditions used to measure them. The water contents

307 of the four Enochrus species (60-68\% of fresh mass) were consistent with the typical $62 \%$ of

308 most beetles (Hadley 1994). Water loss rates, ranging from 2.2 to $3.6 \%$ of initial mass at $20 \%$

$309 \mathrm{RH}$, appear to be comparable to those reported for the extraordinary desiccation resistant $P$.

310 muticus, which lost ca. $5.4 \%$ of initial mass per hour under more severe conditions $(0 \% \mathrm{RH})$

311 (Arlian and Staiger 1979). Nevertheless, the total water losses that the studied species reached

312 after the desiccation treatment (Table S2) were close to the limit of dehydration tolerance of

313 most insects (20 - 30\% of water content) (Hadley 1994). Although such water loss was measured

314 under an unrealistic humidity in natural conditions $(20 \% \mathrm{RH})$, a combination of high

315 temperatures $\left(>30^{\circ} \mathrm{C}\right)$ and low humidity $(40-50 \% \mathrm{RH})$ is frequent in the natural habitats of these 
316 species. Prolonged exposures to such conditions in nature may result in extremely stressful

317 conditions and high mortalities of local populations of the studied species, but further research is

318 needed to identify desiccation level and duration thresholds under natural conditions for each

319 particular species.

320 The analysis of traits at the individual level is essential for further exploration of the mechanisms

321 regulating water loss rate. In Enochrus species, water loss rates were positively related to the

322 specimens' initial water content. These relationships were relatively weak $\left(\mathrm{r}^{2}<0.5\right)$ due to high

323 inter-individual variation in both traits, which might be associated to age, sex or the

324 physiological state of the individuals (e.g. Chown et al. 1999; Lyons et al. 2014; Matzkin et al.

325 2007). Despite this variability, resistance to water loss seems to be partly a function of individual

326 water content, as beetles with a higher initial proportion of water lost it faster than those with

327 lower values. This suggests that a critical level of water loss may induce active mechanisms for

328 water conservation (e.g. changes in cuticular permeability), which might be "relaxed" when

329 organismal water content rises above this threshold. Such regulation is concordant with the

330 nonlinearity of water loss following exposure to desiccation found in many fully terrestrial

331 insects (e.g. Arlian and Staiger 1979; Benoit et al. 2007).

332 Although we used cuticle content as a potential surrogate of cuticle permeability, since increased

333 cuticle thickness is associated with desiccation resistance in insects adapted to arid conditions

334 (Crowson 1981; Elias 2010), this trait showed no relationship with water loss rates in any

335 Enochrus species. In addition, in interspecific comparisons, the species with the highest mean

336 water loss rate had the highest cuticle content. A recent study also showed that cuticle thickness

337 in adult mosquitoes appeared not to affect desiccation resistance (Reidenbach et al. 2014).

338 Therefore, the validity of cuticle thickness as proxy for cuticular permeability could be very 
339 different across taxa and may perhaps have low resolution for intra-generic comparisons. In

340 some terrestrial insects, changes in the composition and quantity of cuticular hydrocarbons

341 appear to be the main mechanism through which they can modulate cuticular permeability (e.g.

342 Hadley 1978; Nelson and Lee 2004; Stinziano et al.2015; Toolson 1982). In aquatic insects,

343 similar mechanisms may shape responses to dehydration occurring both in exposure to air or

344 hyperosmotic aquatic medium but to date even basic cuticular properties in such taxa have

345 received little study (but see Alarie et al. 1998 for an example).

346 Despite the fact that many previous studies suggest that body size affects water loss rate in

347 arthropods (e.g. Chown et al.1998; Lighton et al. 1994; Prange and Pinshow1994) our results

348 suggest that both interspecific and inter-individual size differences do not significantly affect

349 desiccation resistance in these water beetles. Although large size (lower area-to-volume ratio)

350 might be expected to be beneficial for survival under desiccating conditions (Chown et al. 1998;

351 Schmidt-Nielsen 1984), important trade-offs could arise as a result of increases in body size

352 (Chown and Gaston 2010; Chown and Klok 2003). This could be particularly true in the case of

353 aquatic insects living in fluctuating or temporary waters, such as the beetles studied here, where

354 rapid larvae development and small body size are common, alongside other r-selected traits

355 (Millán et al. 2011; Williams 1985).

\section{Conclusions}

357 This study is the first to explore both interspecific and inter-individual variation in desiccation resistance traits within a group of closely related aquatic insects. Our results suggest that control

359 of both water loss rate and water content may be key mechanisms for dealing with desiccation stress in adult water beetles and suggest an association between salinity tolerance and desiccation 
361 resistance. Further studies are required to evaluate the ecological and evolutionary consequences

362 of interspecific variation in key desiccation resistance traits, but our results point to habitat-

363 mediated differences (saline $v s$. freshwater) in the vulnerability of water beetle species to a

364 higher frequency and intensity of droughts expected in semi-arid regions.

\section{Acknowledgments}

366 We thank F. Picazo, S. Guareschi and all members of the research group Aquatic Ecology of the

367 University of Murcia for helping with beetle species field collection and M. Botella-Cruz for

368 helping with experimental procedures. The manuscript was greatly improved by the suggestions

369 of Tomas Ditrich and two other anonymous reviewers.

\section{Figure captions}

371 Fig 1. Interspecific comparison of desiccation resistance traits in Enochrus species. Letters below the

372 boxes indicate significant differences between species (Bonferroni post-hoc tests, $\mathrm{P}<0.05$ ). Boxplots

373 represent Q25, median and Q75, whiskers are Q10 and Q90 and dots are outliers.

374 Fig 2. Relationships between individual water loss rates (WLR) and initial water content $\left(\mathrm{WC}_{0}\right)$, cuticle 375 content $(\mathrm{CC})$ and fresh mass $\left(\mathrm{M}_{0}\right)$ for Enochrus species. P-values and deviance $\left(\mathrm{D}^{2}\right)$ are showed for the 376 statistically significant relationships $(\mathrm{P}<0.05)$.

\section{References}

Abellán P., Millán A. \& Ribera I. (2009) Parallel habitat-driven differences in the 
beetles. Molecular Ecology 18, 3885-3902.

383

384

Addo-Bediako A., Chown S.L. \& Gaston K.J. (2001) Revisiting water loss in insects: a large scale view. Journal of Insect Physiology 47, 1377-1388.

Alarie Y., Joly H. \& Dennie D. (1998) Cuticular hydrocarbon analysis of the aquatic beetle Agabus anthracinus Mannerheim (Coleoptera: Dytiscidae). The Canadian Entomologist 130, 615-269.

Arlian L. \& Staiger T. (1979) Water balance in the semiaquatic beetle, Peltodytes muticus. Comparative Biochemistry and Physiology Part A: Molecular \& Integrative Physiology 62A, 1041-1047.

Arribas P., Andújar C., Abellán P., Velasco J., Millán A. \& Ribera I. (2014) Tempo and mode of the multiple origins of salinity tolerance in a water beetle lineage. Molecular Ecology 23, $360-373$.

Arribas P., Velasco J., Abellán P., Sánchez-Fernández D., Andújar C., Calosi P., Millán A., Ribera I. \& Bilton D.T. (2012) Dispersal ability rather than ecological tolerance drives differences in range size between lentic and lotic water beetles (Coleoptera: Hydrophilidae). Journal of Biogeography 39, 984-994.

Beament J.W.L. (1961) The waterproofing mechanism of arthropods II. The permeability of the cuticle of some aquatic insects. Journal of Experimental Biology 38, 277-290.

Benoit J.B. (2010) Water management by dormant insects: Comparisons between dehydration resistance during summer aestivation and winter diapause. Progress in Molecular and 
402

403

404

405

406

407

408

409

410

411

412

413

414

415

416

417

418

419

420

421

Subcellular Biology 49, 209-229.

Benoit J.B., Lopez-Martinez G., Michaud M.R., Elnitsky M.A., Lee Jr R.E. \& Denlinger D.L. (2007) Mechanisms to reduce dehydration stress in larvae of the Antarctic midge, Belgica antarctica. Journal of Insect Physiology 53, 656-667.

Benoit J.B., Patrick K.R., Desai K., Hardesty J.J., Krause T.B. \& Denlinger D.L. (2010)

Repeated bouts of dehydration deplete nutrient reserves and reduce egg production in the mosquito Culex pipiens. Journal of Experimental Biology 213, 2763-2769.

Benoit J.B., Yoder J.A., Rellinger E.J., Ark J.T. \& Keeney G.D. (2005) Prolonged maintenance of water balance by adult females of the American spider beetle, Mezium affine Boieldieu, in the absence of food and water resources. Journal of Insect Physiology 51, 565-573.Bilton D.T. (2014) Dispersal in Dytiscidae. In: Ecology, Systematics, and Natural History of Predaceous Diving Beetles (Coleoptera: Dytiscidae) (Ed. D.A. Yee) pp. 387- 407. Springer, New York.

Bradley T. (2009) Animal osmoregulation. Oxford University Press, New York, USA.

Cannings S.G. (1981) The influence of salinity on the cuticular permeability of Cenocorixa bifida hungerfordi Lansbury (Hemiptera: Corixidae ). Canadian Journal of Zoology 59, $1505-1509$.

Céspedes V., Pallarés S., Arribas P., Millán A. \& Velasco J. (2013) Water beetle tolerance to salinity and anionic composition and its relationship to habitat occupancy. Journal of Insect Physiology 59, 1076-84. 
422 Chown S.L. (1993) Desiccation resistance in six sub-Antarctic weevils (Coleoptera:

423 Curculionidae): humidity as an abiotic factor influencing assemblage structure. Functional

$424 \quad$ Ecology 7, 318-325.

425 Chown S.L. \& Gaston K.J. (2010) Body size variation in insects: a macroecological perspective.

426 Biological Reviews 85, 139-169.

427 Chown S.L. \& Klok C.J. (2003) Water-balance characteristics respond to changes in body size in 428 subantarctic weevils. Physiological and Biochemical Zoology 76, 634-643.

429 Chown S.L., Le Lagadec M.D. \& Scholtz C.H. (1999) Partitioning variance in a physiological 430 trait: desiccation resistance in keratin beetles (Coleoptera, Trogidae). Functional Ecology $431 \quad 13,838-844$.

432

433

434

435

436

437

438

439

440

441

Chown S.L. \& Nicolson S. (2004) Insect Physiological Ecology. Mechanisms and patterns. Oxford University Press, Oxford.

Chown S.L., Pistorius P.A. \& Scholtz C.H. (1998). Morphological correlates of flightlessness in southern African Scarabaeinae (Coleoptera: Scarabaeidae): testing a condition of the water conservation hypothesis. Canadian Journal of Zoology 76, 1123-1133.

Chown S.L., Sørensen J. \& Terblanche J. (2011) Water loss in insects: an environmental change perspective. Journal of Insect Physiology 57, 1070-1084.

Crowson R.A. (1981). The Biology of the Coleoptera. Academic Press, London.

Datry T., Pella H., Leigh C., Bonada N. \& Hugueny B. (2016) A landscape approach to advance intermittent river ecology. Freshwater Biology 61, 1200-1213. 
442 Davy-Bowker J. (2002) A mark and recapture study of water beetles (Coleoptera: Dytiscidae) 443 group of semi-permanent and temporary ponds. Aquatic Ecology 36, 435-446.

444 DeVito J., Meik J.M., Gerson M.M. \& Formanowicz D.R. Jr. (2004) Physiological tolerances of 445 three sympatric riparian wolf spiders (Araneae: Lycosidae) correspond with microhabitat 446 distributions. Canadian Journal of Zoology 82, 1119-1125.

447 Dudley R. (2000). The Biomechanics of Insect Flight. Princenton University Press, Princeton, $448 \quad$ NJ.

Edney E.B. (1977) Water Balance in Land Arthropods. Springer, Berlin.

450

451

452

453

454

455

456

457

458

459

460

461

Elias S.A. (2010) Advances in Quaternary Entomology. Developments in Quaternary Sciences, 12. Elsevier, Amsterdam.

Elnitsky M.A., Benoit J.B., Lopez-Martinez G., Denlinger D.L. \& Lee R.E.J. (2009) Osmoregulation and salinity tolerance in the Antarctic midge, Belgica antarctica: seawater exposure confers enhanced tolerance to freezing and dehydration. Journal of Experimental Biology 212, 2864-2871.

Evans D.H. (2008) Osmotic and ionic regulation. Cells and Animals. CRC Press. Boca Ratón, FL.

Everatt M.J., Convey P., Worland M.R., Bale J.S. \& Hayward S.A.L. (2014) Contrasting strategies of resistance $v s$. tolerance to desiccation in two polar dipterans. Polar Research 33, 22963.

Filipe A.F., Lawrence J.E. \& Bonada N. (2013) Vulnerability of stream biota to climate change 
462

463

464

465

466

467

468

469

470

471

472

473

474

475

476

477

478

479

480

in mediterranean climate regions: A synthesis of ecological responses and conservation challenges. Hydrobiologia 719, 331-351.

Gereben B.A. (1995) Co-occurrence and microhabitat distribution of six Nebria species (Coleoptera: Carabidae) in an alpine glacier retreat zone in the Alps, Austria. Arctic Antarctic and Alpine Research 27, 371-379.

Gibbs A.G. \& Matzkin L.M. (2001) Evolution of water balance in the genus Drosophila. Journal of Experimental Biology 204, 2331-2338.

Gibbs A.G., Rajpurohit S. (2010) Cuticular lipids and water balance. In: Insect Hydrocarbons: Biology, Biochemistry, and Chemical Ecology. (Ed. G.J. Blomquist \& A.G. Bagnères). pp. 100-120. Cambridge University Press, Cambridge.

Gray E.M. \& Bradley T.J. (2005) Physiology of desiccation resistance in Anopheles gambiae and Anopheles arabiensis. American Journal of Tropical Medicine and Hygiene 73, 553-559.

Hadley N. (1978) Cuticular permeability of desert tenebrionid beetles: correlations with epicuticular hydrocarbon composition. Insect Biochemistry 8, 17-22.

Hadley N.F. (1994) Water Relations of Terrestrial Arthropods. Academic Press, San Diego.

Harrison J.F., Woods H.A. \& Roberts, S.P. (2012) Ecological and environmental physiology of insects. Oxford Univeristy Press, New York.

Hershkovitz Y. \& Gasith A. (2013) Resistance, resilience and community dynamics in mediterranean-climate streams. Hydrobiologia 719, 59-76. 
481 Hjalmarsson A. E., Bergsten J. Monaghan, Michael T. (2015) Dispersal is linked to habitat use in

482

483

484

485

486

487

488

489

490

491

492

493

494

495

496

497

498

499

500

501

59 species of water beetles (Coleoptera: Adephaga) on Madagascar. Ecography 38, 732739.

Hof C., Brandle M., Dehling D.M., Munguia M., Brandl R., Araujo M.B., Rahbek C. (2012) Habitat stability affects dispersal and the ability to track climate change. Biology Letters $\mathbf{8}$, $639-643$.

Hoffmann A.A. \& Harshman L.G. (1999) Desiccation and starvation resistance in Drosophila: Patterns of variation at the species, population and intrapopulation levels. Heredity 83, 637643.

Holdgate M.W. (1956) Transpiration through the cuticles of some aquatic insects. Journal of Experimental Biology 33, 107-118.

Holmstrup M., Hedlund K. \& Boriss H. (2002) Drought acclimation and lipid composition in Folsomia candida: implications for cold shock, heat shock and acute desiccation stress. Journal of Insect Physiology 48, 961-970.

Juliano S. A., O’Meara G.F., Morrill J.R. \& Cutwa M.M. (2002) Desiccation and thermal tolerance of eggs and the coexistence of competing mosquitoes. Oecologia 130, 458-469.

Kellermann V., van Heerwaarden B., Sgrò C.M. \& Hoffmann A.A. (2009) Fundamental evolutionary limits in ecological traits drive Drosophila species distribution. Science 325, 1244.

Lapinski W. \& Tschapka M. (2014) Desiccation resistance reflects patterns of microhabitat choice in a Central American assemblage of wandering spiders. Journal of Experimental 
503

504

505

506

507

508

509

510

511

512

513

514

515

516

517

518

519

520

521

522

Larned S.T., Datry T., Arscott D.B. \& Tockner K. (2010) Emerging concepts in temporary-river ecology. Freshwater Biology 55, 717-738.Lawrence J. E., Lunde K. B., Mazor R. D., Bêche L. A., Mcelravy, E. P. \& Resh V. H. (2010) Long-term macroinverebrate responses to climate change: implications for biological assessment in mediterranean-climate streams. Journal of the North American Benthological Society 29, 1424-1440.

Le Lagadec M.D., Chown S.L. \& Scholtz C.H. (1998) Desiccation resistance and water balance in southern African keratin beetles (Coleoptera, Trogidae): The influence of body size and habitat. Journal of Comparative Physiology Part B: Biochemical, Systemic, and Environmental Physiology 168, 112-122.

Levis N. A., Yi S.X. \& Lee R.E. (2012) Mild desiccation rapidly increases freeze tolerance of the goldenrod gall fly, Eurosta solidaginis: evidence for drought-induced rapid coldhardening. Journal of Experimental Biology 215, 3768-3773.

Lighton J.R.B., Quinlan M.C. \& Feener D.H. Jr. (1994) Is bigger better? Water balance in the polymorphic desert harvester ant Messor pergandei. Physiological Entomology 19, 325334.

Lopez-Martinez G., Benoit J.B., Rinehart J.P., Elnitsky M.A., Lee Jr R.E. \& Denlinger D.L. (2009) Dehydration, rehydration, and overhydration alter patterns of gene expression in the Antarctic midge, Belgica antarctica. Journal of Comparative Physiology Part B:

Biochemical, Systemic, and Environmental Physiology 179, 481-491. Lyons C.L., Coetzee M., Terblanche J.S. \& Chown S.L. (2014) Desiccation tolerance as a function of age, sex, 
523

524

525

526

527

528

529

530

531

532

533

534

535

536

537

538

539

540

541

542

humidity and temperature in adults of the African malaria vectors Anopheles arabiensis and Anopheles funestus. Journal of Experimental Bology 217, 3823-3833.

Matzkin L.M., Watts T.D. \& Markow T.A. (2007) Desiccation resistance in four Drosophila species. Fly 1, 268-273.

Millán A., Sánchez-Fernández D., Abellán P., Picazo F., Carbonell J.A., Lobo J.M. \& Ribera I. (2014) Atlas de los coleópteros acuáticos de España peninsular. Ministerio de Agricultura, Alimentación y Medio Ambiente, Madrid.

Millán A., Velasco J., Gutiérrez-Cánovas C., Arribas P., Picazo F., Sánchez-Fernández D., Abellán P. (2011) Mediterranean saline streams in southeast Spain: What do we know? Journal of Arid Environments 75, 1352-1359.

Montes C. \& Martino P. (1987) Las lagunas salinas españolas. In: Bases científicas para la protección de los humedales españoles. pp. 95-145. Real Academia de Ciencias Exactas, Físicas y Naturales de Madrid, Madrid.

Nelson D.R. \& Lee Jr R.E. (2004) Cuticular lipids and desiccation resistance in overwintering larvae of the goldenrod gall fly, Eurosta solidaginis (Diptera: Tephritidae). Comparative biochemistry and physiology Part B: Biochemistry \& Molecular Biology 138, 313-320.

Pallarés S., Arribas P., Céspedes V., Millán A. \& Velasco J. (2012) Lethal and sublethal behavioural responses of saline water beetles to acute heat and osmotic stress. Ecological Entomology 37, 508-520.

Prange H.D. \& Pinshow B. (1994) Thermoregulation of an unusual grasshopper in a desert 
environment: the importance of food source and body size. Journal of Thermal Biology 19, $75-78$.

545

546

547

548

549

550

551

552

553

554

555

556

557

558

559

560

561

562

563

R Core Team (2015). R: A language and environment for statistical computing. R Foundation for Statistical Computing, Vienna, Austria. URL http://www.R-project.org/.

Reidenbach K.R., Cheng C., Liu F., Liu C., Besansky N.J. \& Syed Z. (2014) Cuticular differences associated with aridity acclimation in African malaria vectors carrying alternative arrangements of inversion 2La. Parasites \& Vectors 7, 176.

Renault D. \& Coray Y. (2004) Water loss of male and female Alphitobius diaperinus (Coleoptera: Tenebrionidae) maintained under dry conditions. European Journal of Entomology 101, 491494.

Ribera I. (2008) Habitat constraints and the generation of diversity in freshwater macroinvertebrates. In: Aquatic Insects: Challenges to Populations (Eds: J. Lancaster \& R. A. Briers). pp. 289-311. CAB International Publishing, Wallingford.

Robson B.J., Chester E.T. \& Austin C.M. (2011) Why life history information matters: Drought refuges and macroinvertebrate persistence in non-perennial streams subject to a drier climate. Marine and Freshwater Research 62, 801-810.

Schmidt-Nielsen K. (1984) Scaling: Why is animal size so important?. Cambridge University Press, Cambridge.

Schultz T.D., Quinlan M.C. \& Hadley N.F. (1992) Preferred body temperature, metabolic physiology, and water balance of adult Cicindela longilabris: a comparison of populations from boreal habitats and climatic refugia. Physiological Zoology 65, 226-242. 
564 Stinziano J.R., Sové R.J., Rundle H.D. \& Sinclair B.J. (2015) Rapid desiccation hardening

565 changes the cuticular hydrocarbon profile of Drosophila melanogaster. Comparative

566 biochemistry and physiology Part A, Molecular \& Integrative Physiology 180, 38-42.

567 Strachan S.R., Chester E.T. \& Robson B.J. (2015) Freshwater invertebrate life history strategies 568 for surviving desiccation. Springer Science Reviews 3, 57-75.

569 Stubbington R., Gunn J., Little S., Worrall T.P. \& Wood P.J (2016) Macroinvertebrate seedbank

570 composition in relation to antecedent duration of drying and multiple wet-dry cycles in a

571 temporary stream. Freshwater Biology 61, 1293-1307.

572 Suemoto T., Kawai K. \& Imabayashi H. (2004) A comparison of desiccation tolerance among 12 573 species of chironomid larvae. Hydrobiologia 515, 107-114.

574 Terblanche J.S., Sinclair B.J., Klok C.J., McFarlane M.L. \& Chown S.L. (2005) The effects of 575 acclimation on thermal tolerance, desiccation resistance and metabolic rate in Chirodica 576 chalcoptera (Coleoptera: Chrysomelidae). Journal of Insect Physiology 51, 1013-1023.

577 Toolson E.C. (1982). Effects of rearing temperature on cuticle permeability and epicuticular lipid 578 composition in Drosophila pseudoobscura. Journal of Experimental Zoology 222, $249-253$.

579 Wigglesworth V.B. (1945) Transpiration through the cuticle of insects. Journal of Experimental $580 \quad$ Biology 21, 97-114.

581 Williams A.E. \& Bradley T.J. (1998) The effect of respiratory pattern on water loss in 582 desiccation-resistant Drosophila melanogaster. Journal of Experimental Biology 201, $583 \quad 2953-2959$. 
584 Williams W.D. (1985) Biotic adaptations in temporary lentic waters with special reference to 585 those in semi-arid regions. In: Perspectives in Southern Hemisphere Limnology (Eds: B.R. 586 Davies \& R.D. Walmsley). pp 85-110. Junk Publishers, Dordrecht.

587 Wissinger S.A., Brown W.S. \& Jannot J.E. (2003) Caddisfly life histories along permanence 588 gradients in high-altitude wetlands in Colorado (U.S.A.). Freshwater Biology 48, 255589 270.Woods H.A. \& Singer M.S. (2001) Contrasting responses to desiccation and starvation $590 \quad$ by eggs and neonates of two Lepidoptera. Physiological and Biochemical Zoology 74, 594$591 \quad 606$.

592 Yoder J.A., Benoit J.B., Nelson B.W., Main L.R. \& Bossley J.P. (2015) Behavioral correction to 593 prevent overhydration and increase survival by larvae of the net-spinning caddisflies in 594 relation to water flow. Journal of Experimental Biology 218, 363-369.Zhang J., Goyer C. \& 595 Pelletier Y. (2008) Environmental stresses induce the expression of putative glycine-rich 596 insect cuticular protein genes in adult Leptinotarsa decemlineata (Say). Insect Molecular 597 Biology 17, 209-216. 


\section{Table 1 (on next page)}

Habitat parameters of Enochrus species, together with collection sites. 
1 Table 1. Habitat parameters of Enochrus species, together with collection sites.

\begin{tabular}{|c|c|c|c|c|c|c|}
\hline \multirow[t]{2}{*}{ Species } & \multicolumn{3}{|c|}{ Habitat preferences } & \multicolumn{3}{|c|}{ Collection sites } \\
\hline & $\begin{array}{l}\text { Conductivity range }{ }^{\mathrm{a}} \\
\qquad\left(\mathrm{mS} \mathrm{cm} \mathrm{cm}^{-1}\right)\end{array}$ & $\begin{array}{c}\text { Conductivity optimum }{ }^{\mathrm{b}} \\
\left.\qquad(\mathrm{mS} \mathrm{cm})^{-1}\right)\end{array}$ & Habitat type & Locality & Latitude & Longitude \\
\hline E. halophilus & $0.47-23.00$ & 6.25 (subsaline) & Temporary-Lentic & Pétrola pond, Albacete & 38.8471 & -1.5589 \\
\hline E. politus & $1.50-133.40$ & 19.32 (hyposaline) & Intermittent-Lotic & Chícamo stream, Murcia & 38.2175 & -1.0511 \\
\hline E. bicolor & $2.10-86.00$ & 34.96 (mesosaline) & Temporary-Lentic & Mojón Blanco pond, Albacete & 38.8002 & -1.4301 \\
\hline E. jesusarribasi & $14.90-160.00$ & 62.14 (hypersaline) & Intermittent-Lotic & Rambla Salada stream, Murcia & 38.1263 & -1.1182 \\
\hline
\end{tabular}

2 a Field conductivity data were obtained from Biodiversity database of the Aquatic Ecology Research Group, University of Murcia.

3 b Ranges of conductivity of each category $\left(\mathrm{mS} \mathrm{cm}^{-1}\right)$ : Freshwater: $<1$, Subsaline: 1-10, Hyposaline: 10-30, Mesosaline: 30-60, Hypersaline: $>60$ (Montes and 4 Martino 1987). 


\section{Table 2 (on next page)}

GLM results on interspecific differences in fresh mass $\left(M_{0}\right)$, water loss rate (WLR), water content $\left(\mathrm{WC}_{0}\right)$ and cuticle content $(\mathrm{CC})$ across Enochrus species ( $\mathrm{N}=20$ per species). 
1 Table 2. GLM results on interspecific differences in fresh mass $\left(\mathrm{M}_{0}\right)$, water loss rate (WLR), water

2 content $\left(\mathrm{WC}_{0}\right)$ and cuticle content (CC) across Enochrus species ( $\mathrm{N}=20$ per species).

3

4

\begin{tabular}{lcccc}
\hline Trait & Predictors & df & $\begin{array}{c}\text { F-value/ } \chi^{2} \text { a } \\
(\text { Explained deviance) }\end{array}$ & P \\
\hline $\mathrm{M}_{0}(\mathrm{mg})$ & $\mathrm{Sp}$ & 3 & 37.627 & $<0.001$ \\
& $\mathrm{Sex}$ & 1 & 14.206 & $<0.001$ \\
& Sp x Sex & 3 & 0.607 & 0.613 \\
& & & $(0.651)$ &
\end{tabular}

7

8

WLR (\% $\left.\mathrm{M}_{0} \mathrm{~h}-1\right)$

Sp 3

$\mathrm{M}_{0} \quad 1$

2.718

$<0.001$

Sex 1

0.126

0.161

0.004

0.799

9

Sp x Sex 3

0.007

0.990

10

11

$\mathrm{WC}_{0}\left(\% \mathrm{M}_{0}\right)$

Sp 3

$(0.397)$

12

$\begin{array}{ll}\mathrm{M}_{0} & 1\end{array}$

22.086

$<0.001$

Sex 1

1.387

0.243

4.736

0.033

Sp x Sex

0.335

0.800

(0.519)

$\mathrm{CC}\left(\% \mathrm{M}_{0}\right)$

$\begin{array}{cc}\text { Sp } & 3 \\ \mathrm{M}_{0} & 1 \\ \text { Sex } & 1 \\ \text { Sp x Sex } & 3\end{array}$

27.019

$<0.001$

3.067

0.085

0.027

0.870

1.629

0.192

(0.593)

${ }^{a}$ F-value for GLMs with gaussian distribution $\left(\mathrm{M}_{0}, \mathrm{WC}\right.$ and $\left.\mathrm{CC}\right) ; \chi^{2}$ for GLMs with gamma distribution (WLR)

${ }^{\mathrm{b}}$ (null deviance - residual deviance/null deviance) 


\section{Figure 1 (on next page)}

Interspecific comparison of desiccation resistance traits in Enochrus species.

Letters below the boxes indicate significant differences between species (Bonferroni post-hoc tests, $\mathrm{P}<0.05)$. Boxplots represent Q25, median and Q75, whiskers are Q10 and Q90 and dots are outliers. 


\section{Figure 2 (on next page)}

Relationships between individual water loss rates (WLR) and initial water content $\left(W_{0}\right)$, cuticle content (CC) and fresh mass $\left(\mathrm{M}_{0}\right)$ for Enochrus species.

P-values and deviance $\left(D^{2}\right)$ are showed for the statistically significant relationships $(P<0.05)$. 
A

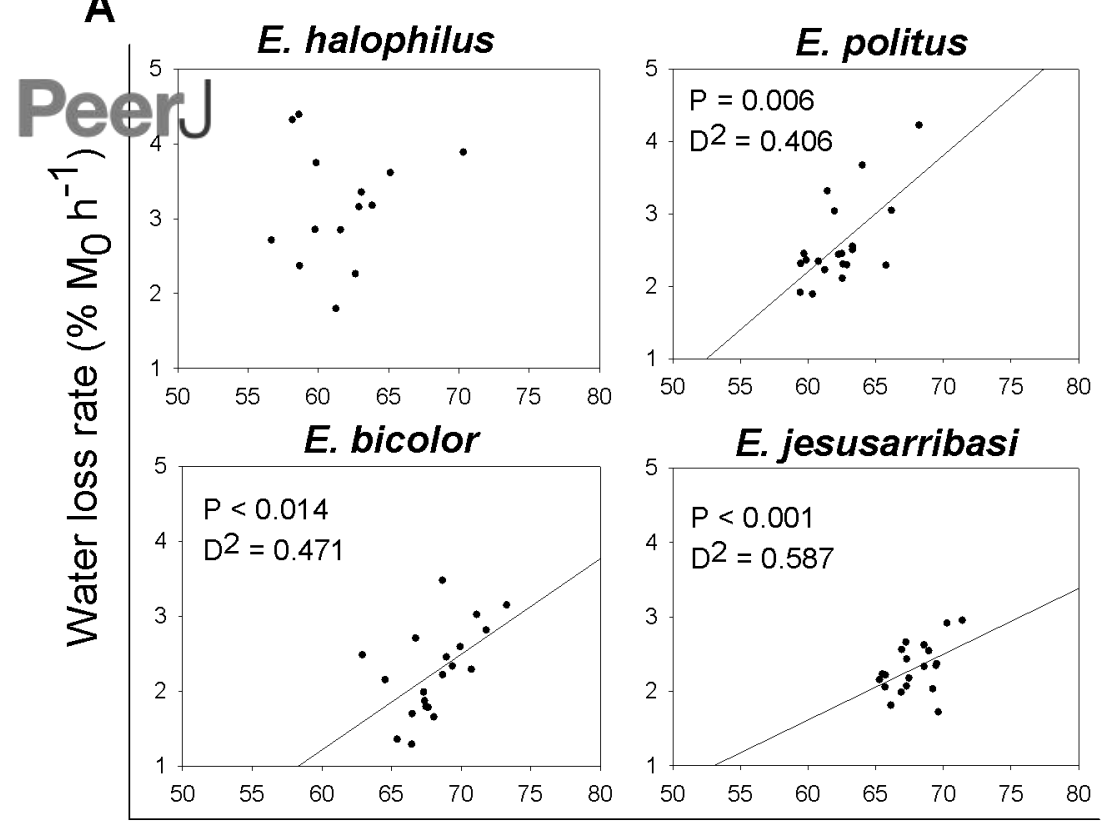

Water content (\% Mo)

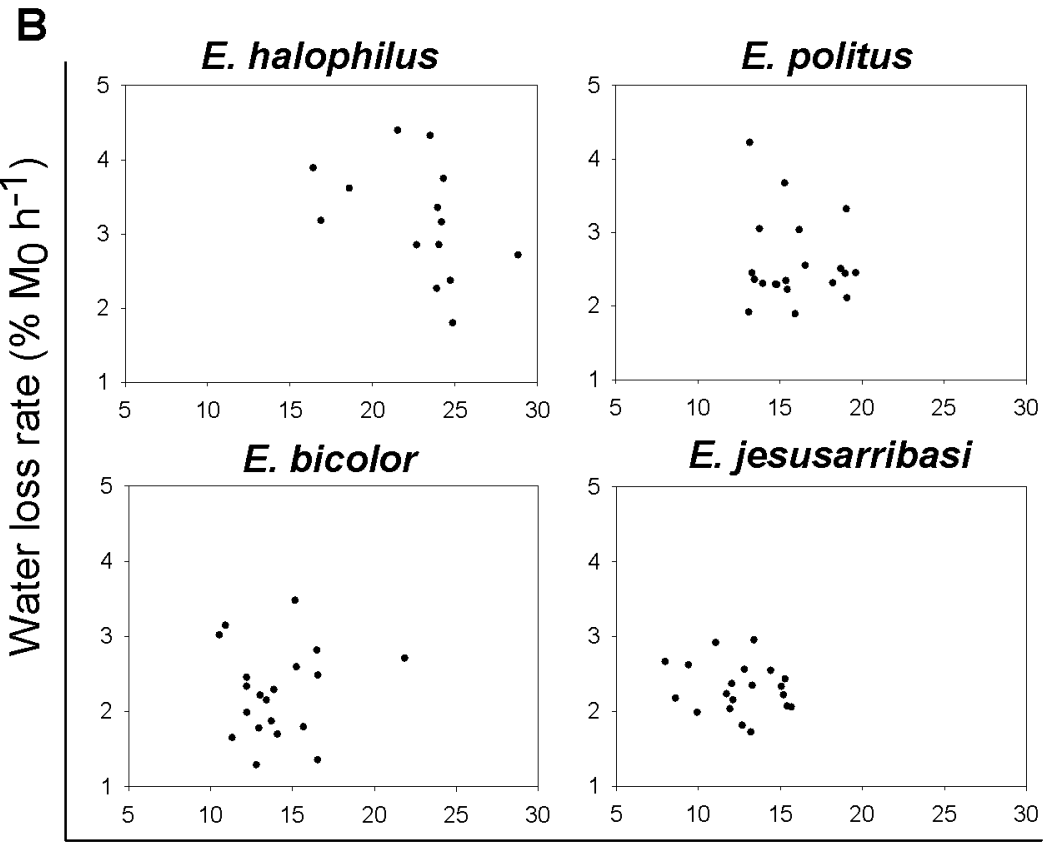

Cuticle content (\% Mo)

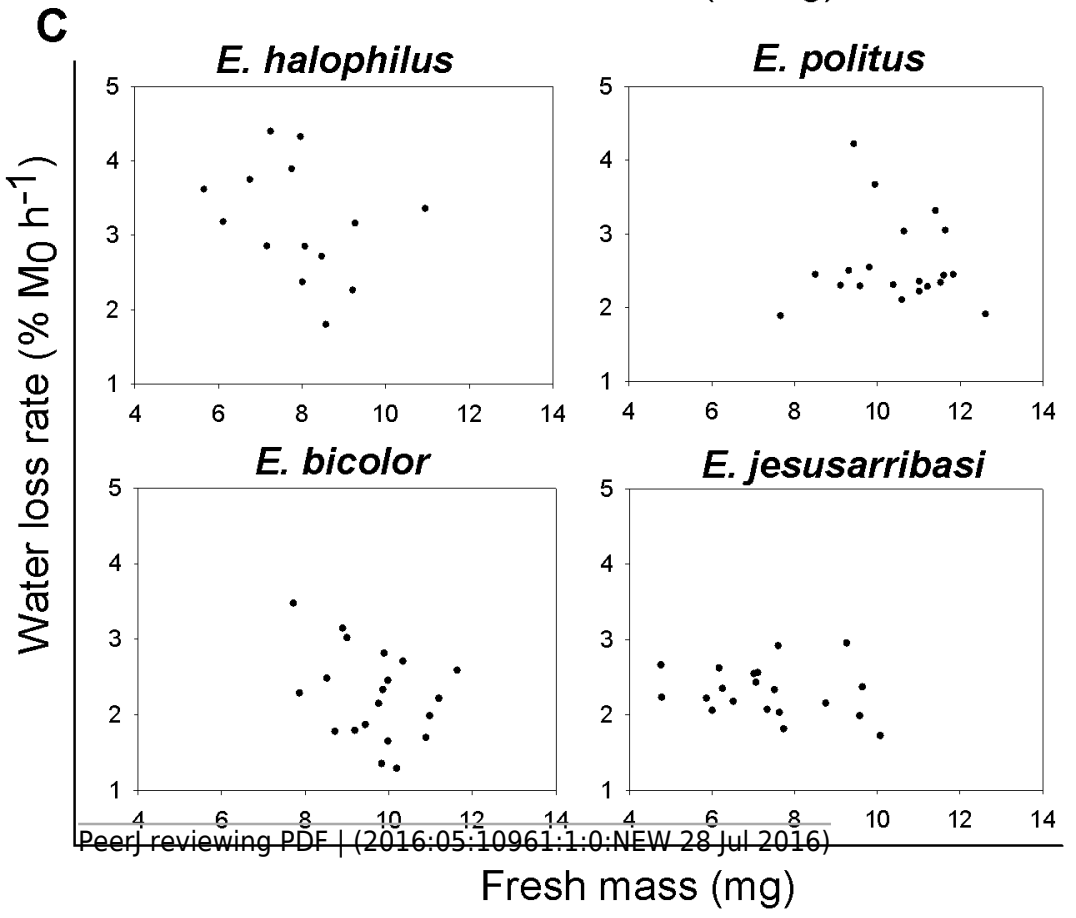

